\title{
PROPERTIES OF CORONAL MASS EJECTIONS PROPAGATING IN THE HELIOSPHERE
}

\author{
G. A. Porfir'eva, G. V. Yakunina \\ State Sternberg Astronomical Institute, \\ Moscow University, Moscow, RU-119991, Russia, \\ galina-porfirieva@yandex.ru \\ (Received November 21, 2011)
}

\begin{abstract}
Propagating through the heliosphere coronal mass ejection (CME) could change its direction and velocity. The direction of propagation of a CME defines if the CME would arrive in the Earth or not. The data on the propagation of coronal mass ejections (CMEs) registered in recent decades have been collected. The results of white-light observations with the LASCO SOHO and instruments onboard STEREO A and B spacecrafts are used. In the nearest corona velocities of different CMEs may range from $(2-3) \times 10^{2} \mathrm{~km} \mathrm{~s}^{-1}$ to $(4-5) \times 10^{2} \mathrm{~km} \mathrm{~s}^{-1}$ up to $(1-3) \times 10^{3} \mathrm{~km} \mathrm{~s}^{-1}$ for the fastest ones. Propagating through the solar corona CMEs change their shapes demonstrating self-similar expansion, flattening or no expansion. At an early stage CMEs might deflect in the meridional direction for $\sim\left(2^{\circ}-30^{\circ}\right)$ from high latitudes to the heliospheric current sheet (HCS). Simultaneous observations from STEREO A and B have shown the azimuthal deflection for $5^{\circ}-30^{\circ}$ up to the distances of $40-70 R_{\odot}$. The models explaining the observed phenomena of CMEs deflections are briefly discussed.
\end{abstract}

Key words: Sun, corona, coronal mass ejection, space weather.

PACS number(s): 96.60.ph

\section{INTRODUCTION}

Plasma outflows from the solar corona are of numerous types by their energies, kinematics, morphology and temporal evolution. The solar wind is continuously blowing out from the corona. White-light observations with the LASCO SOHO C2 and C3 have revealed plasma outflows from coronal streamers. Eruptions of filaments, explosions of solar flares, ejections of jets are observed. Coronal mass ejections (CMEs) are the most energetic events on the Sun being the ejections of large clouds of magnetic plasma into the space resulting from magnetic reconnection in low layers and related to the opening of a magnetic field and the overall reconstruction of magnetic field in corona. CMEs propagation through the solar corona is accompanied by radio bursts, shocks and energetic particles. Since the first observations with OSO-7 CMEs and associated events such as flares, erupted filaments and radio bursts are thoroughly investigated [1$13]$.

The launch of the SOHO and STEREO with a better capability of observations gave new data. The observations from the Solar and Heliospheric Observatory (SO$\mathrm{HO}$ ) provide us with a view of a CME projected on the plane of the sky and images of CMEs in the nearest heliosphere up to $15-30 \mathrm{R}_{\odot}$. It is impossible to determine the full velocity, trace and true shape of the CME having a view from one point. The Solar Terrestrial Relations Observatory (STEREO) separated in space gives simultaneously two images viewed from the points and permits to establish more real velocity, acceleration, direction of propagation and three-dimensional (3D) configuration of CMEs tracing CMEs up to the Earth and farther. The CMEs are optically thin and we deal with the intensities integrated along the line of sight. The emission of the white corona is due to the Tompson scatter of the white light of the Sun scattered by electrons of the corona.

The data on propagation of coronal mass ejections (CMEs) registered during the last decades have been collected. The results of white-light (W-L) observations with the Large Angle Spectrometric Coronograph (LASCO) SOHO and coronographs COR1, COR2 and Heliospheric Imagers HI1 and HI2 aboard the STEREO A and $\mathrm{B}$ are used. The CMEs kinematical evolution, deflection of their traces and changes of their shapes are considered. The direction of propagation of a CME defines if the CME would arrive in the Earth or not. The time of coming depends on the velocity of the CME.

\section{OBSERVATION AND RESULTS}

\section{A. Instruments}

CMEs are observed in white-light and ultra-violet spectral lines with the instruments aboard the space observatory SOHO. LASCO/SOHO includes two coronographs with separate fields of view: $\mathrm{C} 2\left(24^{\prime \prime}, 2-6 R_{\odot}\right)$ and C3 $\left(112^{\prime \prime}, 4-30 R_{\odot}\right)$, giving white-light images of the outer corona. EIT/SOHO (Extreme Ultraviolet Imaging Telescope) obtains spectrally resolved images of the solar disc and of the limb corona to radial distances of 1.3-1.7 $R_{\odot}$ in the lines: Fe IX-X $171 \AA$, Fe XII $195 \AA$, Fe XV $284 \AA$ and permits to see the origin of the CME on the solar disc. STEREO A and B spacecrafts coronographs observe in WL with better temporal and space resolutions comparing with LASCO SOHO. For COR1 FOV covers the distances from $1.5 R_{\odot}$ to $4.0 R_{\odot}$, for COR2 FOV is from $2.0 R_{\odot}$ to $15 R_{\odot}$. Heliospheric imagers HI1 is pointed $13.2^{\circ}$ away from the Sun showing a $20^{\circ}$ field 


\section{G. A. PORFIR'EVA, G. V. YAKUNINA}

near the ecliptic plane $\left(15-90 R_{\odot}\right)$, HI2 is pointed $53.4^{\circ}$ from the Sun and has a $70^{\circ}$ field centered around the ecliptic plane $\left(90-300 R_{\odot}\right)$.

\section{B. CMEs characteristics in the nearest heliosphere}

Observations aboard SOHO gives a rich information in the nearest heliosphere up to the distances of 20-30 $R_{\odot}$. CMEs properties vary substantially inside the LAS$\mathrm{CO}$ FOV. At the initiation phase the $\mathrm{CME}$ velocities are mainly low (10-100 $\left.\mathrm{km} \mathrm{s}^{-1}\right)$ increasing during acceleration phase and reaching their peaks during flare peaks for impulsive events. For gradual events, usually not associated with flares, acceleration phase might be long. The CME accelerations range from several $\mathrm{m} \mathrm{s}^{-2}$ to several dozens or hundreds of $\mathrm{m} \mathrm{s}^{-2}$ and more. So the CME on 1997 November 6 had a very large acceleration $a \sim 7300$ $\mathrm{m} \mathrm{s}^{-2}$ and the peak velocity $V$ of $2150 \mathrm{~km} \mathrm{~s}^{-1}$ [7]. Un- successful CMEs could after deceleration return to the solar surface [14].

The ranges of CME properties are presented in Table 1. In the 1st column the considered properties are listed, in the second one their ranges are given composed by us on the results from $[7,10,13,15]$. In the $3 d, 4$ th and 5 th columns the averages according to the data from $[16$, 15,13 are presented. The periods of observations are 1996-2003 in [16], 1996-2008 in [15] and 1996-2006 in [13]. In [15] the average values of $V$ and $W$ are for all CMEs and for the non-narrow CMEs with angular width $W>30^{\circ}$, correspondingly. In [13] average $V$ is for all flare-associated CMEs, average $a$ is for the CMEs accompanied by flares of $\mathrm{M}$ class and stronger, average values of $W$ are for the CME associated with the flares of $\mathrm{B}$ and $\mathrm{X}$ class, correspondingly. We must remember that the values of $V, a$ and $W$ are suffered from the projection effect. Daily rate $(D R)$ means numbers of CMEs per day and $D R$ ranges from the solar minimum to solar maximum.

\begin{tabular}{|l|c|ccc|}
\hline Properties & Range & \multicolumn{3}{|c|}{ Average } \\
\hline velocity $V \mathrm{~km} \mathrm{~s}^{-1}$ & $20<V<3000$ & 489 & $466-470$ & $495 \pm 8$ \\
acceleration $a \mathrm{~m} \mathrm{~s}^{-2}$ & $-218<a<7300$ & & & $-3.7 \pm 1.3$ \\
energy $E$ erg & $10^{27}<E<10^{33}$ & & \\
mass $M$ g & $10^{12}<M<10^{16}$ & $1.6 \times 10^{15}$ & & \\
angular width $W^{\circ}$ & $5<W<360$ & 47 & $41-60$ & $42-80$ \\
daily rate $D R$ & $0.5^{a}<D R<6^{b}$ & & & \\
\hline
\end{tabular}

${ }^{a} \mathrm{CME}$ per day during solar minimum

${ }^{b} \mathrm{CME}$ per day during solar maximum

Table 1. The range of CMEs characteristics in the nearest corona.

\section{Velocities of CMEs with LASCO SOHO and STEREO A and B}

A typical CME has a three-part structure with a bright leading edge, a following dark void and a trailing bright core being the erupted prominence material. The velocity of the CME is defined by the trajectory of its leading edge or center of its mass. They might differ. The velocities $V$ seem to increase with the height in the COR1 and COR2 SOHO FOV in different ranges for fast and slow CMEs as it has been shown by Vourlidas et al. [6], who analyzed 11 flux-rope CMEs observed aboard LASCO SOHO. For the fast CMEs $V=600-900 \mathrm{~km} \mathrm{~s}^{-1}$ at 15 $R_{\odot}$ and for the slow CMEs $V=200-250 \mathrm{~km} \mathrm{~s}^{-1}$ at $16-$ $20 R_{\odot}$. The evolution of speed with the height for the fast CME on 1997 February 23 and slow CME on 1997 November 1 is presented in Figure 1 based on Figure 3 from [6]. The CME velocity is shown by the dashed line with the asterisk and escape speed is demonstrated by the dash-dotted line, $a$ is the average acceleration. The usual CMEs achieve the escape velocity at $\sim 8-10 R_{\odot}$.

STEREO data permit to follow CMEs up to the distances of $100-150 R_{\odot}$. Using the HI1 STEREO B images, Wang et al. [17] investigated the propagation and expansion of the flux-rope slow gradually accelerated CME observed on 2007 October 8 up to the distances of $\sim 70$
$R_{\odot}$. The CME showed a constant velocity $(\simeq 22.5 \mathrm{~km}$ $\left.\mathrm{s}^{-1}\right)$ phase and then a constant acceleration $\left(7.6 \mathrm{~m} \mathrm{~s}^{-2}\right)$ phase [18]. At the distances of $50-70 R_{\odot}$ the velocity of the leading edge of the CME reached $270 \mathrm{~km} \mathrm{~s}^{-1}$ as it can be seen in Figure 2 constructed by us on the basis of Figure 3 from [17]. The expansion velocity was possibly about $90-100 \mathrm{~km} \mathrm{~s}^{-1}$ and the radius of the CME was 20 $R_{\odot}$ when its leading edge reached the distance of $\sim 70$ $R_{\odot}$. Simultaneous observations from STEREO A and B stations might give $3 \mathrm{D}$ velocities up to $100-150 R_{\odot}$.
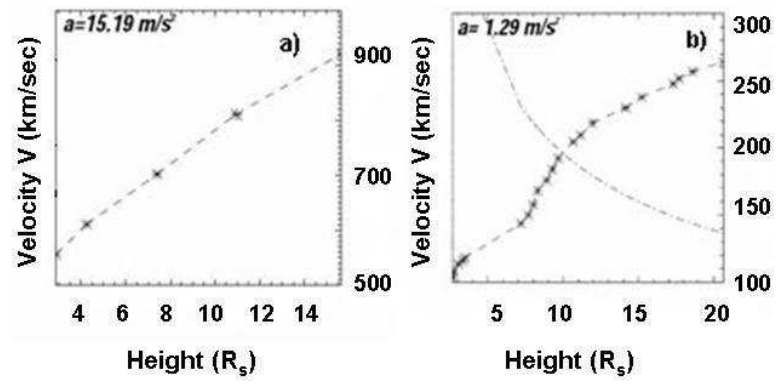

Fig. 1. Evolution of velocity with height for the fast CME on 1997 February 23 (a) and slow CME on 1997 November 1 (b) LASCO SOHO (by Fig. 3 and Fig. 5 from [6] correspondingly). 


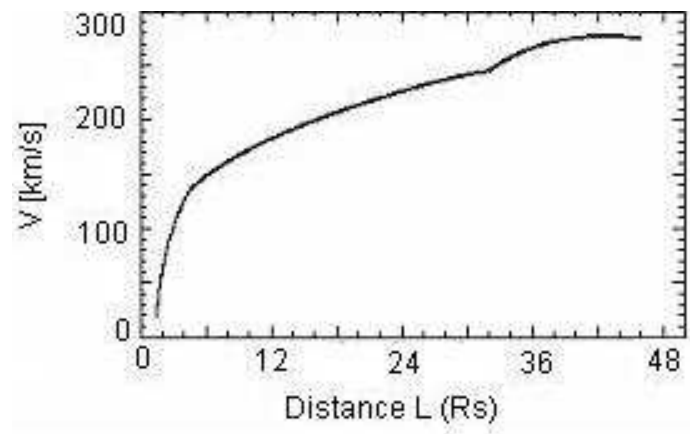

Fig. 2. Evolution of velocity of the CME on 2007 October 8 observed with HI1 STEREO B; $L$ is the distance, measured in Rs, of the CME center from the solar surface (based on the Fig. 3 from [17]).

\section{Observed CME shape and magnetic field}

Comparing the velocities of the CMEs fronts with their center-of mass velocities Vourlidas et al. [6] investigated the evolution of the shapes of 11 flux-rope CMEs observed with LASCO SOHO during 1997-1998. Six CMEs showed self-similar expansion or no expansion preserving their shapes. For 5 CMEs the shape become progressively flattening. A flattening of an CME during its propagation is predicted by some models [19, 20].
Comparison of the velocities of the front $V_{f}$ (plus) and center of mass $V$ (asterisk) for 4 CMEs is shown in Figure 3 based on Figure 8 from [6]. The accelerations $a$ and $a_{f}$ of the center of mass and front of the CME are correspondingly indicated. In the first row CMEs on 1997 April 13 and 1997 November 1 demonstrate progressive flattening. Their leading edges are moving with a lesser acceleration than the centers of mass. The CME on 1997 October 30 (low left) shows no expansion, and at every time moment its $V_{f}$ is approximately equal to its $V$. The CME on 1997 August 13 (low right) shows a self-similar expansion and its $V_{f}$ is exceeding its $V$ for almost the constant value $\sim 40 \mathrm{~km} \mathrm{~s}^{-1}$ during all the visible propagation.

The three-dimensional structure of the CMEs is not clear up till now if they are bubbles, or plane loops, or arcades of loops, or curved flux ropes. The observations provide us with a view of a CME projected on the plane of the sky. The CMEs are optically thin, and we deal with the intensities integrated along the line of sight. Analyzing the shapes of the CMEs and magnetic field topology of the corresponding source regions (SRs) where the CMEs originated Cremades, Bothmer [21] and Cremades et al. [22] concluded that the observed structure of CME depends on the location and orieintation of the neutral line (NL) of the associated SR.
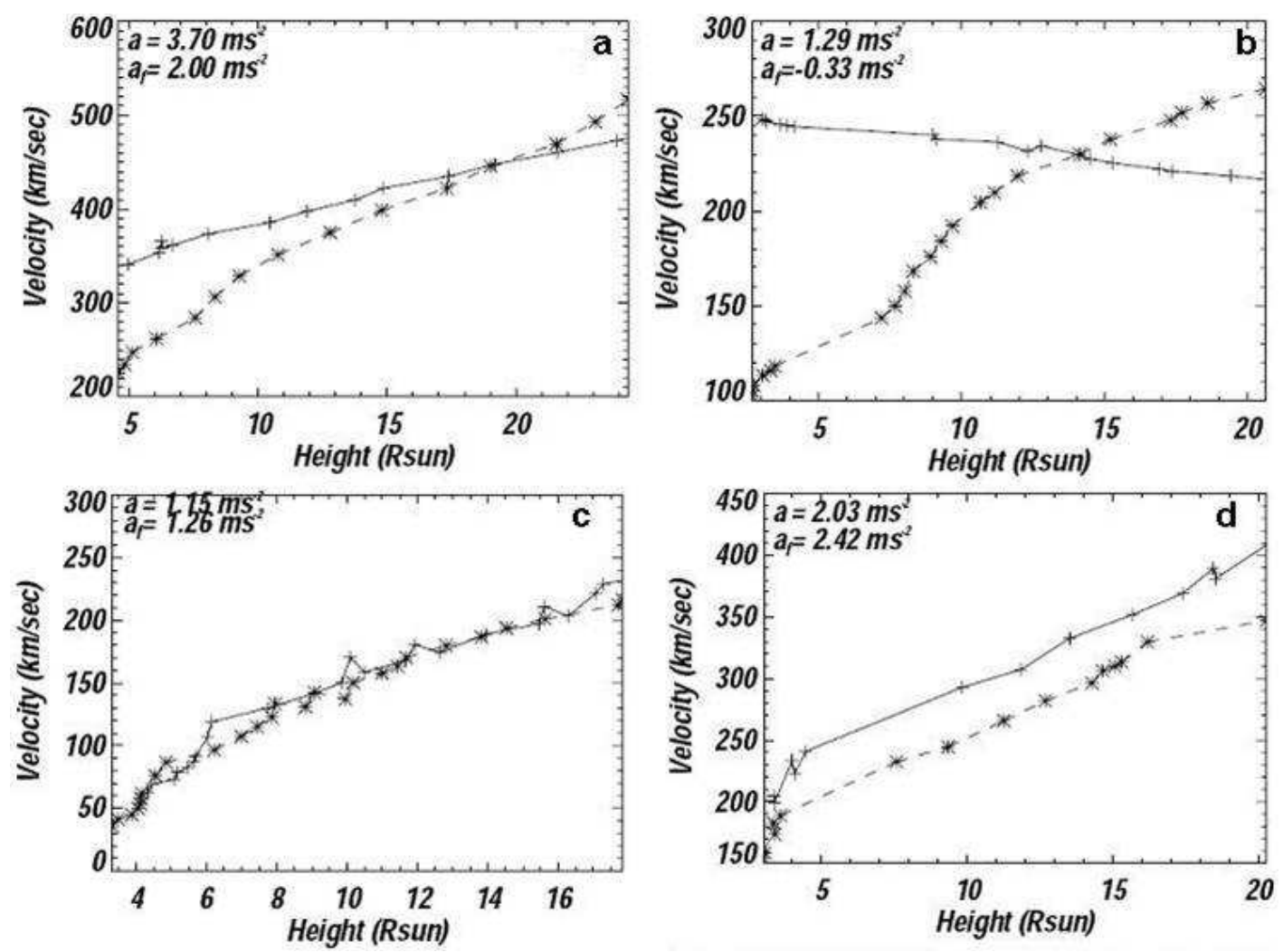

Fig. 3. Comparison of the velocities of the front (plus) and center of mass (asterisk) for 4 CMEs: a) 1997 April 13 flattening, b) 1997 November 1 - flattening, c) 1997 October 30 - no expansion, d) 1997 August 13 - self-similar expansion (by Fig. 8 from [6]). 
In Figure $4 \mathrm{a}$ the $\mathrm{SR}$ is on the east limb and NL is perpendicular to the limb. The CME on 2002 January 4 is visible along its flux rope axis, i. e. along its axis of symmetry. We see a loop-like bright leading edge. In Figure $4 \mathrm{~b}$ the SR is on the west limb. The NL is parallel to the limb. On 2002 May 22 we see the flux-rope CME from its side. A side-viewed prominence with the overlying loop system gives a diffused shape of the CME with a flattening leading edge and a broad diffused core. The corresponding source regions (EUV EIT SOHO) with superposed magnetic fields of different polarities (MDI SO$\mathrm{HO}$ ) are seen in Figures 4d and 4e. The SRs are encircled by ovals. In Figure 4c the CME of 2008 April 26, observed as the halo type CME, is shown. A CME is visible as a brightness around the solar disc when it arises close to the central solar meridian relatively to the observer. The halo CMEs might be symmetric and asymmetric.

The schemes of CME projections for 4 limb events are presented in Figure 5 for the cases both when CMEs originate on the visible front side of the Sun (on left of the Figure) and when CMEs arise on the invisible back side of the Sun (on the right of the Figure). NL is the neutral line. The NLs are inclined to the solar equator in both south and north hemispheres according the Hale-Nichols law. We see examples of structured and diffused CMEs.

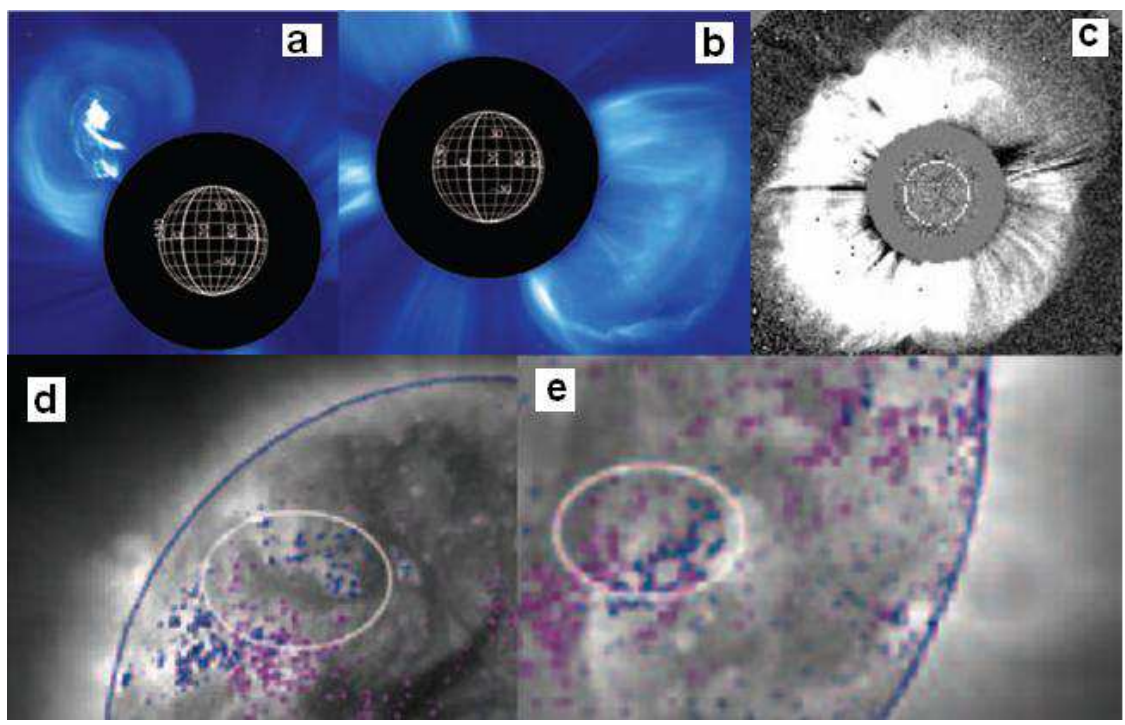

Fig. 4. (Color online) (a) Structured CME on 2002 January 4, COR2 LASCO SOHO (by Fig. 13 [21]), (b) diffused CME on 2002 May 22, COR2 LASCO SOHO (by Fig. 14 [21]). Corresponding source regions in $\lambda 304 \AA$ EIT SOHO, circled by ovales, with superimposed magnetic fields MDI SOHO and neutral lines NLs perpendicular (d) and parallel (e) to the solar limb. (c) Halo CME on 2008 April 26, COR2 STEREO B (by Fig. 1.6.6 [16]).
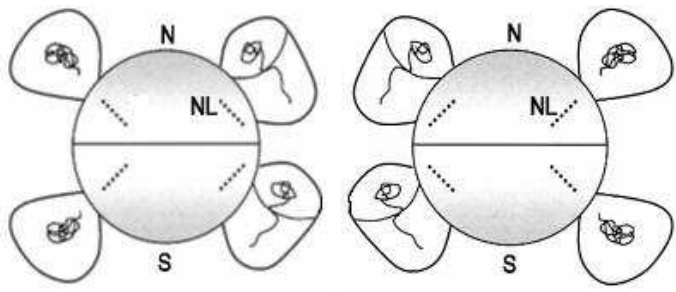

Fig. 5. Schemes of projections for four limb CMEs. On the left - front side cases, on the right - back side cases (according to Fig. 15 and Fig. 16 from [21]).

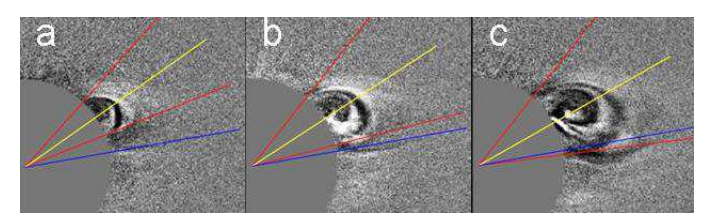

Fig. 6. (Color online) Deflected slow gradually accelerated CME on 2007 October 8 by COR1 and COR2 STEREO B (based on Fig. 1 from [18]).

\section{E. Latitudinal deflection of CME}

At the solar minimum a CME at an early stage may deflect for $20-30^{\circ}$ from high latitudes toward the lower ones and beyond $5-6 R_{\odot}$ it propagates at almost constant position angle, as for the case of the slow gradually accelerated helical CME on 8 October [17, 18]. A similar slow deflected CME on 8 November 2008 was studied by Kilpua et al. [23]. Slow CMEs have difficulties to overcome the straining forces of the overlying magnetic field, they obey the polar magnetic field of the Sun, i. e. CMEs tend to propagate from the regions with a high magnetic energy density to the sites of a lower magnetic energy density near heliospheric current sheet (HCS).

The deflected slow CME on 8 October 2007, observed aboard STEREO B, is shown in Figure 6 (by Figure 1 from [18]). The CME appeared at the west limb and was associated with an eruptive prominence. No strong flare was observed. The eruption of the prominence was registered at 07:00 UT in $\lambda$ 304 $\AA$. The CME showed a helical structure and Wang et al. [17] supposed that the CME was seen along its axis and the observed images were 
cross-sections of the magnetic helical rope. For each moment radial direction and CME width are indicated.

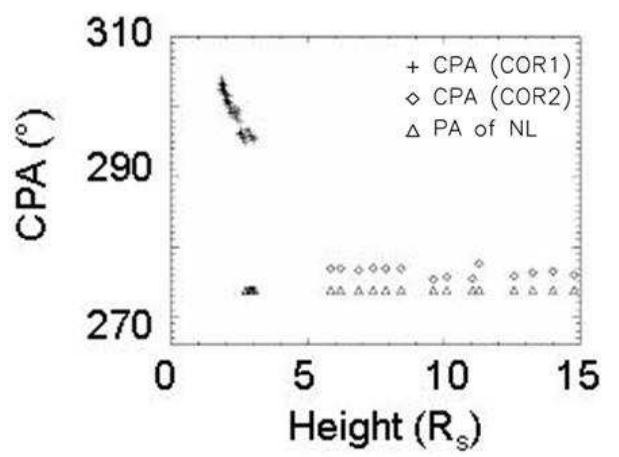

Fig. 7. Central position angles of the CME on 2007 October 8 in dependence from height: $1(+)$ - COR1 STEREO, $2(\diamond)$ - COR2 STEREO , $3(\triangle)$ - the modelled PAs of HCS (according to Fig. 2 from [18]).

Propagating in the FOV of the COR1 STEREO B the CME continuously deflected toward the ecliptic plane from the position angle $\mathrm{PA} \sim 306^{\circ}$ to $\mathrm{PA} \sim 276^{\circ}$ and beyond $5.5 R_{\odot}$ in the $\mathrm{COR} 2 \mathrm{FOV}$ it propagated almost radially. In Figure 7 the evolution of central position angle (CPA) of the CME measured from the north to the east is shown (by Fig. 2 from [18]).

Earlier the CMEs deflection in the meridian plane was investigated for example during 1972 and 1974 in [24]. The average deflection of $\sim 2.2^{\circ}$ toward the ecliptic plane was found. In [21, 22] on the basis of same observations with the LASCO, EIT, MDI SOHO and base-ground $\mathrm{H}_{\alpha}$ the images of 124 structured flux-rope CMEs cases during the period of 1996-2002 with the known information on the associated source regions (SRs) were analyzed. The SRs regions were identified by pre- and post-eruptive events such as prominences, expanding loops and dimmings. The PA of an AR (or a flare) is calculated from its heliographic coordinates. The spatial and temporal coincidence between the CME and its SR was necessary.

Comparing the positions angles (PAs) of the CMEs and SRs they found that during 1996-1998 (near minimum) the central PAs of the structured CMEs deflected for about $20^{\circ}$ to lower latitudes toward the solar equator. At times of the high activity (1999-2002) the deviations $\delta$ fluctuated towards the solar poles or equator without a systematical trend. Yashiro et al. [11] investigated the spatial relation between associated flares and CMSs comparing their PAs. For 1996-2005 LASCO SOHO observations they found 496 flare-CME pairs considering limb events. They concluded that the average difference between flare PAs and CME central PAs was of $\sim 17^{\circ}$.

The simultaneous observations in white-light from different view-points made with the wide-angle imagers HI1 and HI2 aboard STEREO A and B give a possibility to track a CME remotely from the Sun almost to the Earth and to derive the CME shape and direction of its propagation trough the heliosphere. Distinct differences in the CME morphology observed simultaneously from the COR2-A and COR2-B are seen as a result of projection through different lines of sight from two STEREO space crafts. An optically thin structure of a CME is seen differently from different points of view. The examples of observations are shown in Figure 1 [25].

\section{F. Deflection in longitudinal direction}

Different techniques are proposed to reconstruct the true direction of propagation, 3D velocities and configuration [25-32]. The observations by STEREO A and $B$ have shown that CMEs (or their pieces) might deflect monotonically or with some temporal fluctuations toward the east (in some cases) or the west (in other cases) for $5-30^{\circ}$ up to the distances of $100-150 R_{\odot}$. As discussed in [18], inhomogeneities in longitudinal magnetic field strength might cause deflection of an CME in azimuthal direction to the east or to the west.

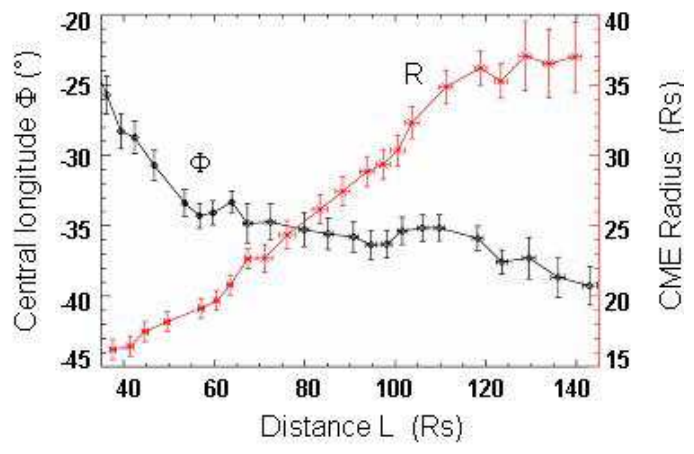

Fig. 8. (Color online) Evolution of central longitude $\Phi$ (curve 1) and radius (curve 2) of the CME on 2008 April 26 with distance (according to Fig. 3 from [31]).

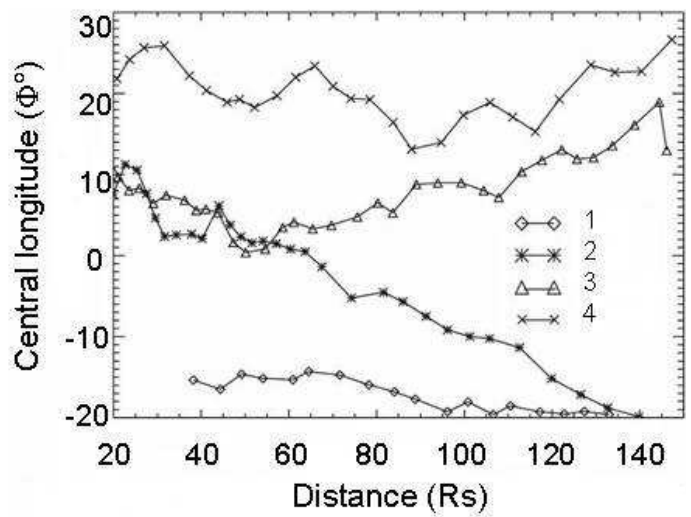

Fig. 9. Evolution of central longitudes $\Phi$ with distance L for different CMEs in 2008: 1 - June 1, 2-August 30, 3 December 12 (fragment 1), 4 - December 12 (fragment 2), according to Fig. 4 from [31].

In [31] two simple models of CME geometry were applied for 4 CMEs observed by both STEREO A and B spacecrafts with HIs, COR1 and COR2 during 2008. In 3 cases (2008 June 2, and two features on December 12) the CMEs propagated almost radially up to the distances of $\sim 170 R_{\odot}$ and the CMEs on April 26 and August 30 were deflected toward the east. The direction of CME propagation is characterized by its central longitude $\Phi$ defined 


\section{G. A. PORFIR'EVA, G. V. YAKUNINA}

as the angle between the direction Sun-Earth and that of the CME propagation. The angle is supposed to be negative to the east from the Earth and positive to the west from the Earth.

The propagation and expansion of the CME on 2008 April 26 is shown in Figure 8 (by Figure 3 bottom right panel from [29]). Curve 1 exposes the change of the CME central longitude. The CME propagated to the east from the direction Sun-Earth. The evolution of the CME radius, measured in solar radius, is presented by curve 2 . The errors are shown by bars. For April $26 \Phi=-11^{\circ}$ at the distance of $20 R_{\odot}$ and $\Phi=-37.5^{\circ}$ at the distance of $130 R_{\odot}[31]$. There was a good agreement with $\Phi=-21^{\circ}$ by Thernisien et al., [29] and $\Phi=-28^{\circ}$ by Wood et al. [32]. The arrival time of the CME to STEREO B was predicted by Lugaz et al., model with an error of about $11^{h}$. The velocity of the CME was defined to be $534 \mathrm{~km}$ $\mathrm{s}^{-1}$ by Lugaz et al. [31] and $543 \mathrm{~km} \mathrm{~s}^{-1}$ by Wood \& Howard [32].

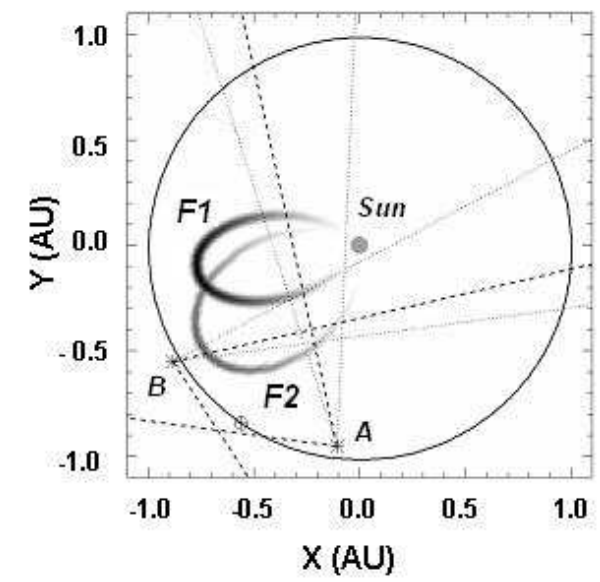

Fig. 10. The locations of the F1 and F2 fronts of the CME on 2008 May 17-18 approaching the Earth, according to 3-D reconstruction by Wood et al. (Fig. 1 [32]). The front F2 is directed right to the STEREO B. FOVs of the HI1 and HI2 are shown.

For June 2 central longitude $\Phi$ was remaining within $-15^{\circ} \pm 1.7^{\circ}$ of radial. At the distance of $75-80 R_{\odot}$ the CME deflected monotonically for $\sim 5^{\circ}$ to the east and then again propagated almost radially at $\Phi=-20^{\circ}$. For December $12 \Phi=10^{\circ} \pm 10^{\circ}$ (fragment 1 of the CME) and $\Phi=20^{\circ} \pm 7^{\circ}$ (fragment 2 of the CME) [31]. The August $30 \mathrm{CME}$ deflected toward the east for $\sim 30^{\circ}$ and crossed the Sun-Earth line as demonstrated in Figure 9 (by Figure 4 from [31]). Triangulation method by Liu et al. [30] gave too approximately a radial propagation for both fragments of the CME on December 12 and longitudes $\Phi$ agree well enough with the results by Lugaz et al. [31].

Wood et al. [32] modeled the appearance of the CME observed on 17 May 2008 with the STEREO A and B by a combination of two expanding outward fronts F1 and F2. The CME was very fast for the solar minimum reaching the peak velocity of $\sim 1120 \mathrm{~km} \mathrm{~s}^{-1}$. Figure 10 shows a slice through the ecliptic plane of the $3 \mathrm{D}$ model of the CME. The shape and orientation of the F1 and F2 fronts approaching 1 AU, locations of Sun, Earth, STEREO A and $\mathrm{B}$ in the heliocentric coordinates XY are shown. The front F1 was oriented $2^{\circ}$ south the ecliptic and $\sim 52^{\circ}$ to the east from the direction Sun-Earth. The front F2 was $8^{\circ}$ north and $\sim 26^{\circ}$ to the east from the direction SunEarth mooving right to the STEREO B spacecraft and was seen as a halo CME. Their ecliptic coordinates longitude $l$ and latitude $b$ were for F1 $l=188^{\circ}, b=-2^{\circ}$ and for $\mathrm{F} 2 l=213^{\circ}, b=8^{\circ}$. The results agree well with the trajectory defined by Thernisien et al. [28] by using a flux rope fitting. F2 moved almost radially (corresponding the position angle of the flare) toward the STEREO $\mathrm{B}$ and $\mathrm{F} 1$ deflected moving away from both STEREO A and STEREO B. An intuitive trial-and-error method of computing synthetic images from an assumed 3D density distribution was used. The distribution was repeatedly altered to obtain the best visual agreement with the observed STEREO appearance of the CME. The most mass was contained in the front F1. The front F2 was significantly weaker. A weak flare B1.7 was registered by GOES close to the center of the solar disc.

Thernisien et al. [28] reconstructed the 3D directions of propagation, velocities and accelerations of the fronts of 26 selected bright CMEs observed since November 2007 to August 2008 by STEREO/COR2 A and B stations. The observed appearance of the CMEs were modeled in an assumption on the flux-rope morphology of the CMEs by Thernisien et al. [27]. A tubular section form the main body attached to two cones corresponding to the legs of the CME. The electron density peak is placed on the surface of the cylindrical shell. So the model is named a hollow "croissant model".

The overall observed shape of the CME is compared with the model representation that is a set of points located on the surface of the "roissant" where the electron density is placed. The leading outer front of the CME on 2008 April 26 was fitted by the projected modeled structure (see Figure 4 from [28]). In COR2 B the CME was seen as a halo one and in the COR2 A the CME was visible from the edge. A good agreement between the model outer contour and CME front is seen in Figure 4 [28]. The azimuth is $-21^{\circ}$, the latitude is $6^{\circ}$ as it discussed above. The 3D velocity has been defined to be of 741 $\mathrm{km} \mathrm{s}^{-1}$ and $3 \mathrm{D}$ acceleration $\mathrm{a}=1.4 \mathrm{~m} \mathrm{~s}^{-2}$. The projected velocity determined by Wood et al. [32] was $541 \mathrm{~km} \mathrm{~s}^{-1}$ as was mentioned above.

\section{SUMMARY}

A brief review of the results of observations of coronal mass ejection during last decades from $\mathrm{SOHO}$ and STEREO is presented. Aarnio et al. [13] examining a very large data set have found that the CMEs, associated with flares, statistically have higher velocities $(495 \pm 8 \mathrm{~km}$ $\left.\mathrm{s}^{-1}\right)$ than the CMEs not associated with flares $(422 \pm 3$ $\mathrm{km} \mathrm{s}^{-1}$ ).

The observations from STEREO A and B have shown that a CME might strongly expand. So for the CME on 
8 October 2007 the radius of the CME became $20 R_{\odot}$ when its leading edge reached the distance of $70 R_{\odot}$ from the Sun [17]. But some CMEs do not demonstrate any expansion [6].

The simultaneous observations with the wide-angle imagers HI1 and HI2 onboard STEREO A and B give a possibility to track a CME to the distances of almost 100-150 $R_{\odot}$ and to derive the CME shape and direction of its propagation trough the heliosphere. Propagating through the nearest corona and heliosphere CMEs early might deflect for $20-30^{\circ}$ both in the meridian plane and in azimuthal direction. Analysis of the evolution of the CMEs propagation in the nearest and further heliosphere is important to predict where the CME will arrive in the Earth or not.

Acknowledgments. We are are very thankful to Dr. G. M. Rudnitskij (Moscow University) for helpful discussions and advice. The work was supported by the grant RFBR 11-02-00843.
[1] J. T. Gosling, E. Hildner, R. M. MacQween, R. H. Munro, A. I. Poland, C. L. Ross, Solar Phys. 48, 389 (1976).

[2] W. J. Wagner , E. Hildner, L. L. House, C. Sawyer, K. V. Sheridan, G. A. Dulk, Astrophys. J. 244, L123 (1981).

[3] O. C. St. Cyr, D. F. Webb, Solar Phys. 136, 379 (1991).

[4] N. Gopalswamy, M. R. Kundu, Solar Phys. 143, 327 (1993).

[5] M. Dryer, Solar Phys. 169, 421 (1996).

[6] A. Vourlidas, P. Subramanian, K. P. Dere, R. A. Howard, Astrophys. J., 534, 456 (2000).

[7] J. Zhang, K. P. Dere, R. A. Howard, M. R. Kundu, S. M. White, Astrophys. J. 559, 452 (2001).

[8] M. D. Andrews, Solar Phys. 218, 261 (2003).

[9] Y.-J. Moon, G. S. Choe, H. Wang, Y. D. Pak, C. Z. Cheng, J. Korean Astron. Soc. 36, 61 (2003).

[10] J. Zhang, K. P. Dere, R. A. Howard, A. Vourlidas, Astrophys. J. 604, 420 (2004).

[11] S. Yashiro, G. Michalek, S. Akiyama, N. Gopalswamy, R. A. Howard, Astrophys. J. 673, 1174 (2008).

[12] G. A. Porfir'eva, G. V. Yakunina, A. V. Oreshina, in Proceedings Conference Solar and Solar-Earth Physics - 2010 (St-Petersburg, 2010), p. 331.

[13] A. N. Aarnio, K. G. Stassun, W. J. Hughes, S. L. McGregor, Solar Phys. 268, 195 (2011).

[14] A. B. Delone, G. A. Porfir'eva, G. V. Yakunina, J. Phys. Stud. 11, 443 (2007).

[15] N. Gopalswamy, S. Akiyama, S. Yashiro, P. Makela, in Astrophys. and Space Science Proceedings (SpringerVerlag, Heidelberg, Berlin, 2010), p. 289.

[16] V. D. Kuznetsov, Plasma heliophysics, IKI RAN, Moscow, 1, 82 (Russian) (2008).

[17] Y. Wang, J. Zhang, Ch. Shen, J. Geophys. Res. 114 (A13), 10104 (2009).
[18] Ch. Shen, Y. Wang, B. Gui, P. Ye, S. Wang, Solar Phys. 269, 389 (2011).

[19] J. Chen, R. A. Howard, G. E. Brueckner, R. Santoro, J. Krall, S. E. Paswaters, O. C. St. Cyr, R. Schwenn, P. Lamy, G. M. Simnett, Astrophys. J. 490, L191 (1997).

[20] B. E. Wood, M. Karovska, J. Chen, G. E. Brueckner, J. W. Cook, R. A. Howard, Astrophys. J. 512, 484 (1999).

[21] H. Cremades, V. Bothmer, Astron. Astrophys. 422, 307 (2004).

[22] H. Cremades, V. Bothmer, D. Tripathi, Adv. Space Res. 38, 461 (2006).

[23] E. K. J. Kilpua, J. Pomoell, A. Vourlidas, R. Vainio, J. Luhmann, Y. Li, P. Schroeder, A. B. Galvin, K. Simunae, Ann. Geophys. 27, 4491 (2009).

[24] R. M. MacQueen, A. J. Hundhausen, C. W. Conover, J. Geophys. Res. 91, 31 (1986).

[25] R. C. Colanino, A. Vourlidas, Astrophys. J. 698, 852 (2009).

[26] N. Lugaz, W. B. Manchester, T. I. Gombosi, Astrophys. J. 627, 1019 (2005).

[27] A. Ternisien, R. A. Howard, A. Vourlidas, Astrophys. J. 652, 763 (2006).

[28] A. Ternisien, A. Vourlidas, R. A. Howard, Solar Phys. 256, 111 (2009).

[29] B. E. Wood, R. A. Howard, Astrophys. J. 702, 901 (2009).

[30] Y. Liu, J. A. Davis, J. G. Luhmann, A. Vourlidas, S. D. Bale, R. P. Lin, Astrophys. J. 710, L82 (2010).

[31] N. Lugaz, J. N. Hernandas-Charpak, I. I. Roussev, C. J. Davis, A. Vourlidas, J. A. Davies, Astrophys. J. 715, 493 (2010).

[32] B. E. Wood, R. A. Howard, A. Ternisien, S. P. Plankett, D. G. Socker, Solar Phys. 259, 163 (2009). 


\title{
ВЛАСТИВОСТІ КОРОНАЛЬНИХ ВИКИДІВ МАСИ, ЩО ПОШИРЮЮТЬСЯ В ГЕЛІОСФЕРІ
}

\author{
Г. А. Порфір'єва, Г. В. Якуніна \\ Державний астрономічний інститут ім. Штернбер'а, \\ Московсъкий університет, Москва, 119991, Росія
}

Проходячи крізь геліосферу, корональный викид мас (CME) може змінювати свою траєкторію і швидкість. Напрям руху визначає, чи досягне СМЕ Землі, чи ні. Зібрано дані про проходження корональних викидів маси (CMEs), зареєстрованих останніми десятиріччями. Використано результати спостережень у білому світлі на коронографах LASCO SOHO и приладах STEREO. У найближчій геліосфері швидкості різних CMEs перебувають у межах від $(2-3) \times 10^{2} \mathrm{~km} \mathrm{~s}^{-1}$ до $(4-5) \times 10^{2} \mathrm{~km} \mathrm{~s}^{-1}$ аж до $(1-3) \times 10^{3} \mathrm{~km}$ $\mathrm{s}^{-1}$ для найбильш швидких CMEs. Поширюючисб у сонячній короні, CMEs змінюють свої форми, демонструючи розширення зі збереженням форми, сплющення чи відсутність розширення. На початковій стадії рух CME може відхилятися в меридіональній площині на $\sim\left(20^{\circ}-30^{\circ}\right)$ від високих широт до геліосферному токовому шару (HCS). Одночасні спостереження із STEREO A and B показали азимутальне відхилення на $5^{\circ}-30^{\circ}$ аж до відстаней 40-70 $R_{\odot}$. Коротко обговорено моделі, що пояснюють спостережувані явища. Використано дані з наукових публікацій та Інтернету. 